\title{
Algumas notas críticas sobre o princípio da presunção de veracidade dos atos administrativos*
}

\section{Critics about the presumption of veracity in administrative procedure act}

\author{
Alexandre Santos de Aragão**
}

\section{RESUMO}

A doutrina brasileira reconhece a presunção relativa de legalidade dos atos da administração pública e tal presunção de veracidade é costumeiramente invocada pela administração pública em detrimento dos administrados. $\mathrm{O}$ presente artigo volta-se para uma análise crítica da presunção de veracidade dos atos administrativos à luz dos princípios da motivação e presunção de inocência, assim como do devido processo legal, de modo a restringir sua aplicação unicamente no âmbito da legitimidade dos atos administrativos e até a impugnação do ato administrativo pelos administrados.

\footnotetext{
* Artigo recebido em novembro de 2011 e aprovado em novembro de 2011.

** Mestre em direito público pela Universidade do Estado do Rio de Janeiro (Uerj) e doutor em direito do Estado pela Universidade de São Paulo (USP). Professor adjunto de direito administrativo da Uerj. Procurador do Estado do Rio de Janeiro e advogado.
} 


\section{PALAVRAS-CHAVE}

Princípio da legalidade - presunção de veracidade - princípio da motivação - devido processo legal - princípio da presunção de inocência - ônus da prova - administração pública - presunção de legitimidade

\section{ABSTRACT}

The Brazilian doctrine recognizes the relative presumption of legality of the public administration's acts and the presumption of veracity is usually invoked by the public administration at the expense of citizens. This article aims to provide a critical analysis of the veracity presumption of the administrative acts in light of the principles of motivation and presumption of innocence, as well as the due process of law, in view of restrict its application to the effect of legitimacy of administrative acts and until the administrative act is contested by the citizens.

\section{KEY-WORDS}

Principle of legality - presumption of veracity - principle of motivation

- due process of law - presumption of innocence - burden of proof

- public administration - presumption of legitimacy

O princípio da legalidade se apresenta como a sujeição de toda atividade administrativa, em sentido amplo, à lei, não podendo atuar sem base legal ou constitucional. ${ }^{1}$

No direito positivo brasileiro, esse postulado, além do disposto no art. 37, está contido no art. 5o, inciso II, da Constituição Federal e, como consequência, obriga o Estado, como administrador dos interesses da sociedade, a agir secundum legem, jamais contra legem ou mesmo praeter legem. ${ }^{2}$

Assentada tal premissa, cabe dizer que a doutrina brasileira reconhece uma presunção relativa de legalidade ${ }^{3}$ como um dos atributos dos atos da ad-

\footnotetext{
${ }^{1}$ MOREIRA NETO, Diogo de Figueiredo. Curso de direito administrativo. Rio de Janeiro: Forense, 2009. p. 74.

${ }^{2}$ Ibid., p. 88.

${ }^{3}$ GUEDES, Demian. A presunção de veracidade e o estado democrático de direito: uma reavaliação que se impõe. In: 2008. p. 245. . Direito administrativo e seus novos paradigmas. Belo Horizonte: Fórum,
} 
ministração pública e, em decorrência dela, presume-se que seus atos sejam verídicos e legítimos, tanto em relação aos fatos por ela invocados como sua causa, quanto no que toca às razões jurídicas que os motivaram.

Nesse diapasão, tal presunção abrange dois aspectos: de um lado, a presunção de verdade, que diz respeito à certeza dos fatos; de outro lado, a presunção da legalidade, pois, se a administração pública se submete à lei, presume-se, conforme mencionado, até prova em contrário, que seus atos sejam praticados com observância das normas legais pertinentes.

Ensina Demian Guedes que

a presunção de legalidade implica que ato exarado pela Administração presume-se legal (conforme o direito), valendo até o reconhecimento jurídico de sua nulidade. Em decorrência de sua presumida correção, tem-se a presunção de veracidade do ato: seus pressupostos fáticos são admitidos como verdadeiros até prova em contrário. ${ }^{4}$

Essa presunção de legitimidade do agir do Estado, que vem expressa no próprio conteúdo democrático do estado de direito, o submete, além da vontade juridicamente positivada - situada no campo do princípio da legalidade - , também à vontade democraticamente expressa. ${ }^{5}$

Nesse sentido, cita-se a pertinente preleção de Diogo de Figueiredo Moreira Neto, afirmando que

a legitimidade se deriva diretamente do princípio democrático, destinada a informar fundamentalmente a relação entre a vontade geral do povo e as suas diversas expressões estatais - políticas, administrativas e judiciárias. Trata-se de uma vontade difusa, captada e definida formalmente a partir de debates políticos, de processos eleitorais e de instrumentos de participação política dispostos pela ordem jurídica, bem como captada e definida informalmente pelos veículos abertos à liberdade de expressão das pessoas, para saturar toda estrutura do Estado democrático, de modo a se tornar necessariamente informativa, em maior ou menor grau, conforme hipótese aplicativa, do exercício de todas as funções e em todos os níveis em que se deva dar alguma integração jurídica de sua ação. ${ }^{6}$

\footnotetext{
${ }^{4}$ Ibid.

${ }^{5}$ MOREIRA NETO. Curso de direito administrativo. 15. ed., 2. tir. Rio de Janeiro: Forense, 2010. p. 89.

${ }^{6}$ Ibid.
} 
Contudo, insta consignar que tal presunção é relativa, juris tantum, admitindo prova ou argumentação em sentido contrário, da mesma forma que a possibilidade de sua impugnação judicial é sempre garantida. ${ }^{7}$

Esse é o princípio que embasa a dita "fé pública"8 atribuída a declarações proferidas por autoridades públicas ou agentes dela delegatários (o tabelião possui fé pública nas declarações que afiança acerca de contratos imobiliários; o guarda de trânsito, ainda que não tenha como obrigar o motorista supostamente alcoolizado a realizar o teste do bafômetro, pode e deve indicar os sinais exteriores de embriaguez, tais como a dificuldade de se expressar verbalmente e o andar com dificuldade, e essas afirmações serão tidas, na esfera administrativa, até prova em contrário, como verdadeiras quanto à existência dos fatos e válidas quanto à sua juridicidade). ${ }^{9}$

Quanto às consequências práticas de tal presunção, o posicionamento doutrinário tradicional defende que a presunção de veracidade do ato administrativo transfere ao particular não apenas o ônus de impugná-lo, mas de fazer prova de sua invalidade ou inveracidade. Nesse sentido, Hely Lopes Meirelles leciona que, entre as consequências da presunção de legitimidade, está "a transferência do ônus da prova da invalidade do ato administrativo para quem a invoca". 1011

\footnotetext{
${ }^{7}$ Curioso como a orientação do direito peruano parece ser a inversa do direito brasileiro, com uma presunção da veracidade das afirmações dos administrados, não da administração pública, como expresso na Ley 27.444/2001, nos seguintes termos: "1.7 - Principio de presunción de veracidad. - En la tramitación del procedimiento administrativo, se presume que los documentos y declaraciones formulados por los administrados en la forma prescrita por esta Ley, responden a la verdad de los hechos que ellos afirman. Esta presunción admite prueba en contrario".

${ }^{8}$ Vale lembrar que o art. 19, inciso II, da Constituição da República, estabelece que um ente político - União, estado, município, Distrito Federal - não pode recusar fé aos documentos dos demais entes.

${ }^{9}$ Por fundamentos diversos, há julgados que também imputam aos particulares o ônus da prova de que não cometeram dano ao meio ambiente: “Trata-se da inversão do ônus probatório em ação civil pública $(\mathrm{ACP})$ que objetiva a reparação de dano ambiental. A Turma entendeu que, nas ações civis ambientais, o caráter público e coletivo do bem jurídico tutelado e não eventual hipossuficiência do autor da demanda em relação ao réu conduz à conclusão de que alguns direitos do consumidor também devem ser estendidos ao autor daquelas ações, pois essas buscam resguardar (e muitas vezes reparar) o patrimônio público coletivo consubstanciado no meio ambiente. A essas regras, soma-se o princípio da precaução. Esse preceitua que o meio ambiente deve ter em seu favor o benefício da dúvida no caso de incerteza (por falta de provas cientificamente relevantes) sobre o nexo causal entre determinada atividade e um efeito ambiental nocivo. Assim, ao interpretar o art. 6o, VIII, da Lei n. 8.078/1990 c/c o art. 21 da Lei n. 7.347/1985, conjugado com o princípio da precaução, justifica-se a inversão do ônus da prova, transferindo para o empreendedor da atividade potencialmente lesiva o ônus de demonstrar a segurança do empreendimento. Precedente citado: REsp 1.049.822-RS, DJe 18/5/2009" (REsp 972.902-RS, rel. min. Eliana Calmon, julgado em 25/8/2009).

${ }^{10}$ LOPES MEIRELLES, Hely. Direito administrativo brasileiro. São Paulo: Malheiros, 1993. p. 141.

${ }^{11}$ Guedes, A presunção de veracidade e o estado democrático de direito, op. cit., p. 246.
} 
Todavia, no atual estado democrático de direito esse princípio tem de ser visto com cautela, sobretudo em seus aspectos incompatíveis com o devido processo legal. A esse respeito, Eduardo García de Enterría e Tomás-Ramón Fernandez ensinam, manifestando como o princípio da motivação deve atuar para mitigar ou abolir o princípio da presunção de veracidade dos fatos alegados pela administração, que "a Administração Pública deve provar no plano material das relações, de maneira que, se deixa de provar, e, todavia, dá como provados determinados fatos, a decisão que adotar será inválida". ${ }^{12}$

Sobre esse aspecto, Demian Guedes elucida que entre os institutos centrais das relações de direito público que demandam uma cuidadosa reavaliação está a presunção de veracidade dos atos administrativos, que, apesar de não contar com fundamentação legal específica, ainda é considerada o "fantasma que apavora quem litiga com a Administração". ${ }^{13-14}$ Diz, ainda, que

por se tratar de uma presunção que não ostenta qualquer respaldo legislativo - especialmente após a redemocratização do país e a promulgação da Constituição de 1988 - , a presunção de veracidade deve ser analisada com certa "suspeita", promovendo-se sua cautelosa oposição a outros valores e princípios administrativos, estes sim, expressos no ordenamento jurídico. ${ }^{15}$

E continua o autor afirmando que "parcela da doutrina pátria entende que a presunção de veracidade cessa diante do questionamento ou da impugnação do ato". Esse é também o entendimento de Bandeira de Mello, que, ao reconhecer a presunção de legalidade dos atos administrativos, lembra que a dita presunção só existe até tais atos serem questionados em juízo. ${ }^{16}$

Nesta mesma esteira, a professora Lúcia Valle Figueiredo assevera que essa presunção se inverte quando os atos forem contestados não apenas em juízo, mas também administrativamente. ${ }^{17}$

\footnotetext{
${ }^{12}$ Eduardo García de Enterría e Tomás-Ramón Fernandez, apud GUEDES, Demian. A presunção de veracidade dos atos da administração pública e o processo administrativo: o dever de fiscalizar provando. Revista Interesse Público, v. 35, p. 108, 2006.

${ }^{13}$ DALLARI, Adilson Abreu; FERRAZ, Sérgio. Processo admnistrativo. São Paulo: Malheiros, 2001. p. 135.

${ }^{14}$ Guedes, A presunção de veracidade e o estado democrático de direito, op. cit., p. 245.

${ }^{15}$ Ibid., p. 244.

${ }^{16}$ Ibid., p. 246.

${ }^{17}$ FIGUEIREDO Lúcia Valle. Curso de direito administrativo. São Paulo: Malheiros, 2001. p. 246.
} 
Paralelamente a tais assertivas, Sérgio Ferraz e Adilson Dallari lembram ser o poder público "quem tem que demonstrar a legalidade de sua atuação". Assim, concluem os autores que "a presunção de legalidade vale até o momento em que o ato for impugnado".

Em nossa opinião, por força do devido processo legal e dos princípios da publicidade, da finalidade e da motivação, a administração pública tem de demonstrar os fatos que ensejaram sua atuação, com o que, portanto, não concordamos com um princípio da veracidade dos fatos alegados pela administração, salvo em casos excepcionais em que essa prova seria, para ela, de impossível realização (a chamada "prova diabólica").

Para Sérgio Ferraz, o processo administrativo é pressuposto de uma atividade administrativa transparente, na qual seja possível perceber as linhas de atuação do poder público e seus desvios. Acerca disso, Nelson Nery $\operatorname{Costa}^{18}$ observa que a verdadeira democracia passa pela abertura e democratização do Estado, com o estabelecimento de um processo administrativo efetivo, no qual o cidadão possa ter reconhecidos seus direitos em face da administração. ${ }^{19}$

O princípio da motivação imputa ao agente público, conforme expõe Diogo de Figueiredo Moreira Neto, "enunciar expressamente - portanto explícita ou implicitamente - as razões de fato e de direito que autorizam ou determinam a prática de um ato jurídico", ${ }^{20}$ viabilizando o controle de legalidade e legitimidade da decisão estatal.

Elucida, ainda, o ilustre jurista que "o princípio da motivação é instrumental e corolário do princípio do devido processo da lei (art. 5o, LIV, CF), tendo necessária aplicação às decisões administrativas e às decisões judiciárias". ${ }^{21}$

A esse respeito, Lúcia Valle Figueiredo afirma que "caberá à Administração provar a estrita conformidade do ato à lei, porque ela (Administração) é quem detém a comprovação de todos os fatos e atos que culminaram com a emanação do provimento administrativo contestado".22

O autor americano Richard H. Gaskins observa que o devido processo legal, no âmbito das instâncias administrativas, traz, como critério de aferição de

\footnotetext{
${ }^{18}$ COSTA, Nelson Nery, Processo administrativo e suas espécies. Rio de Janeiro: Forense, 2003. p. 264.

${ }^{19}$ Ibid., p. 251.

${ }^{20}$ Moreira Neto, Curso de direito administrativo, 15. ed., op. cit., p. 100.

${ }^{21}$ Ibid., p. 100-101.

${ }^{22}$ FIGUEIREDO Lúcia Valle. Curso de direito administrativo. São Paulo: Malheiros, 2001. p. 171.
} 
legitimidade, ônus probatórios para o Estado, que deve satisfazer os interessados e demais críticos da decisão, demonstrando que todas as fontes de erro, personalismos e preferências foram efetivamente afastadas do processo. ${ }^{23}$

Reforçando tal obrigação, a expressa dicção do art. 2oㅡ, parágrafo único, VII da Lei no 9.784/1999, atribuindo à administração brasileira a tarefa de indicar os pressupostos de direito e de fato que determinaram a decisão eleita. $\mathrm{O}$ administrador deve, por conseguinte, diligenciar, sobretudo em processos sancionadores, a busca da verdade real, visando a conferir legitimidade e justiça à solução preceituada.

Sem prova não há legitimação. Se o processo serve apenas para enaltecer a palavra do agente público e, assim, abandonar o cidadão em condições de franca desvantagem, invertendo o princípio da presunção de inocência, não se pode falar em legitimação do poder estatal. ${ }^{24}$

Com efeito, a presunção de veracidade de fatos meramente invocados pela administração pública levaria à presunção de culpa do administrado.

Entretanto, cabe destacar que, em sentido frontalmente contrário a tal presunção de culpa, prevê a Constituição Federal, em seu art. 5o, inc. LV c/c com inc. LVII, o princípio da presunção de inocência. Esse princípio é corolário do princípio do devido processo legal, ${ }^{25}$ e impõe ao órgão acusador "o ônus substancial da prova" ${ }^{26}$ da ilicitude alegada.

Nesse sentido, ensina Luiz Flávio Gomes ${ }^{27}$ que

no que concerne à natureza jurídica da presunção de inocência urge destacar o seguinte: do ponto de vista extrínseco (formal), destarte, no Brasil, o princípio da presunção de inocência configura um direito constitucional fundamental, é dizer, está inserido no rol dos direitos e garantias fundamentais da pessoa (art. 5ํㅜ). Do ponto de vista intrínseco (substancial) é um direito de natureza predominantemente processual, com repercussões claras e inequívocas no campo probatório, das garantias (garantista) e de tratamento do acusado.

\footnotetext{
${ }^{23}$ GASKINS, Richard H. Burdens of proof in modern discourse. Yale University Press, 1975. p. 257.

${ }^{24}$ Ibid., p. 258.

${ }^{25}$ BULOS, Uadi Lammêgo. Constituição Federal anotada. São Paulo: Saraiva, 2007. p. 312. De acordo com esse autor, "a declaração do princípio da presunção de inocência não constava expressamente nas constituições brasileiras passadas. Mesmo assim, a garantia constitucional era dessumida do princípio do contraditório e do princípio da plenitude de defesa".

${ }^{26}$ STF, HC no 67707-0/RS, rel. min. Celso de Mello, DJ 14/8/1992.

${ }^{27}$ GOMES, Luiz Flávio. Sobre o conteúdo processual tridimensional do princípio da presunção de inocência. Revista dos Tribunais, São Paulo, v. 729, p. 382, jul. 1996.
} 
E continua o supracitado autor afirmando que

a doutrina no sentido de que o conteúdo do direito fundamental da presunção de inocência comporta uma dupla exigência: (a) de uma parte, que ninguém pode ser considerado culpado até que assim estabeleça uma sentença condenatória; (b) de outra, que as consequências da incerteza sobre a existência dos fatos e sua atribuição culpável ao acusado beneficiam este, impondo uma carga material da prova às partes acusadoras. O Tribunal Constitucional espanhol, com efeito, no seu julgado 31/81, proclamou os cinco pressupostos necessários para afastar a referida presunção: (a) uma mínima atividade probatória; (b) produzida com as garantias processuais; (c) que a prova seja incriminatória (prova "de cargo"); (d) que da prova se possa deduzir a culpabilidade do acusado; (e) que a prova seja produzida em juízo (imediatidade e oralidade).

Esse princípio também se aplica aos processos administrativos que possam ter como desfecho a imposição de sanções ao administrado. ${ }^{28}$ Como expõe Miguel Beltrán de Felipe, ${ }^{29}$

a presunção de inocência rege sem exceções o ordenamento sancionador e há de ser respeitada na imposição de quaisquer sanções, sejam penais, sejam administrativas..., pois o exercício do ius puniendi em suas diversas manifestações está condicionado (...) ao jogo da prova e a um procedimento contraditório. (...) Em tal sentido, o direito de presunção de inocência comporta: que a sanção esteja baseada em atos e meios probatórios de cargo ou incriminadores da conduta reprovada, que a carga da prova corresponda a quem acusa, sem que ninguém esteja obrigado a provar a sua própria inocência, e que qualquer insuficiência no resultado das provas praticadas (...) deve traduzir-se em um pronunciamento absolutório.

\footnotetext{
${ }^{28}$ OSÓRIO, Fabio Medina. Direito administrativo sancionador. São Paulo: Revista dos Tribunais, 2005. p. 478.

${ }^{29}$ BELTRÁN DE FELIPE, Miguel. Realidad y constitucionalidad en el derecho administrativo sancionador (segunda parte). Revista Jurídica de Castilla - La Mancha, p. 27-28, 2006. grifos nossos.
} 
O Tribunal Constitucional Espanhol já decidiu, nesse sentido, que

a presunção de inocência rege-se sem exceções no ordenamento administrativo sancionador, garantindo o direito de não sofrer sanção que não tenha fundamento em uma prévia atividade probatória sobre a qual o órgão competente possa fundamentar um juízo razoável de culpabilidade. ${ }^{30}$

No sentido da necessidade de comprovação técnica das irregularidades apontadas em processos administrativos, as lições de Egon Bockmann Moreira de que

na medida em que a ampla defesa não pode ser compreendida como singela garantia formal ou abstrata, mas como um dos aspectos da participação efetiva do interessado no aclaramento e formação da decisão da Administração, faz-se necessário o pleno conhecimento das razões dos atos administrativos, pois somente assim poderá manifestar-se a respeito deles. Ou seja: que a atividade processual não consubstancia uma sequência de atos que exija esforços extraordinários do particular a fim de encontrar o real significado dos provimentos administrativos. Somente com plena ciência do porquê das decisões poderá o interessado concordar ou opor-se a elas. (...) Celso Antônio Bandeira de Mello identifica o princípio da motivação como um daqueles essenciais e obrigatórios aos processos administrativos, definindo-o como "o da obrigatoriedade de que sejam explicitados tanto o fundamento fático da decisão, enunciando-se, sempre que necessário, as razões técnicas, lógicas e jurídicas que servem de calço ao ato conclusivo, de molde a poder-se avaliar sua procedência jurídica e racional perante o caso concreto" ${ }^{31}$

Narra Demian Guedes, ${ }^{32}$ invocando os deveres de motivação e de instrução inscritos na Lei do Processo Administrativo (Lei ํo 9.784/1999, arts. 2oㅡ,

\footnotetext{
${ }^{30}$ SSTC 76/1990 e 138/1990 FJ 5, STC 212/1990, de 20 de dezembro. Ponente: D. Jesus Leguina Villa. Apud PONS CÀNOVAS, Ferran. Las medidas provisionales en el procedimiento administrativo sancionador. Madrid/Barcelona: Marcial Pons, 2001. p. 122.

${ }^{31}$ MOREIRA, Egon Bockmann. Processo administrativo: princípios constitucionais e a Lei oㅡ 9.748/99. São Paulo: Malheiros, 2000. p. 258, grifamos.

${ }^{32}$ GUEDES, Demian. A presunção de veracidade dos atos da administração pública e o processo administrativo: o dever de fiscalizar provando. Revista Interesse Público, v. 35, p. 115 e 118, 2006, os últimos grifos são do original.
} 
29, 36 e 37), que Odete Medauar compreende o princípio da verdade material dentro da óptica da oficialidade, apontando que “a Administração não deve se contentar com a versão dos fatos oferecida pelos sujeitos no processo, havendo assim um verdadeiro dever (e não ônus) de prova por parte do Poder Público. (...) Há o dever de a Administração provar suficientemente os fatos que servem de pressuposto do ato".

Em feliz passagem referente ao princípio da verdade material, Lúcia Valle Figueiredo entende que "não se pode mais admitir nesse processo uma demonstração fática lacônica, fundada em uma concepção formal de verdade que fundamenta sua validade exclusivamente na condição de autoridade do agente fiscalizador - caracterizando-se assim hipótese de inaceitável autolegitimação".

No mesmo sentido, Vicenzo Cerulli Irelli ${ }^{33}$ esclarece que

a Administração deve, em primeiro lugar, conhecer a realidade na qual vai incidir a atuação administrativa, apreendendo os fatos e todos os elementos dos quais a realidade se compõe. "Os atos administrativos devem ser fundados em pressupostos de fato rigorosamente verificados e explicitados" (Conselho de Estado, IV 24.02.1981 no 191).

O que o autor resume como uma "necessária instrutoria".

Como afirmam, também, Sérgio Ferraz e Adilson Abreu Dallari, ${ }^{34}$ nos processos administrativos, ainda mais se de caráter sancionatório, os atos da administração não podem ser desvestidos das provas necessárias para aferição da sua legitimidade, no caso, provas técnicas: "aqui a Administração-parte tem que provar suas alegações, sob pena de não as ver reconhecidas (TRF-4 ${ }^{\text {a }}$ R., Ap. cível 96.04.47023-0-RS, rel. juiz Antônio Albino Oliveira, DJU 21/7/99, Seção 2, p. 384)".

Corroborando a tese de que a prova das irregularidades apontadas em processo administrativo compete ao órgão administrativo de controle, cabe, ainda, citar a lição de Nilson Naves (relator do MS 10906), ao afirmar que cabe à administração pública proceder às diligências necessárias para a descoberta da verdade:

\footnotetext{
${ }^{33}$ IRELLI, Vicenzo Cerulli. Corso di diritto amministrativo. Torino: Giappichelli, 2001. p. 38.

${ }^{34}$ FERRAZ, Sérgio; DALLARI, Adilson Abreu. Processo administrativo. São Paulo: Malheiros, 2001. p. $152-153$.
} 
PENAL - APELAÇÃO CRIMINAL - PECULATO QUALIFICADO - ART. 171, § 3o, DO CP - OBTENÇÃO DE BENEFÍCIO PREVIDENCIÁRIO - FRAUDE - VÍNCULO EMPREGATÍCIO FALSO - MATERIALIDADE NÃO COMPROVADA - REFORMA DO DECRETO CONDENATÓRIO.

(...) II - A obrigatoriedade de o beneficiário provar a legitimidade da concessão de seu benefício previdenciário é inversão do ônus da prova e atenta contra o princípio da presunção de inocência $(. ..){ }^{35}$

Destarte, tendo em vista o supracitado princípio da inocência, elucida Demian Guedes que,

à luz dos princípios consagrados na Constituição de 1988, a presunção de veracidade deve ser mitigada desde o processo administrativo, admitindo-se a validade e a correção dos fundamentos de fato do ato da Administração até a sua impugnação pelo particular - uma vez que o processo judicial não é substituto do administrativo, e, de outra parte, as garantias e os princípios jurídico-constitucionais do Poder Público devem incidir sobre suas relações com os particulares independentemente de intervenção judicial. ${ }^{36}$

E segue o ilustre jurista asseverando que

a opção por um Estado Democrático de Direito acarreta a adoção de processos democráticos e controláveis para a formação da verdade. Nesses processos, publicidade e transparência são princípios fundamentais, na medida em que possibilitam uma verificação efetiva da veracidade alegada pela Administração - contando o cidadão, inclusive, com a intervenção do Poder Judiciário. Esses princípios afastam a compreensão tradicional da presunção de veracidade e impõem a exteriorização objetiva dos fatos que fundamentam a atuação estatal, tornando-a controlável sem a necessidade de impor, em desfavor do particular, ônus probatórios de fatos negativos, que muitas vezes impossibilitam o exercício de seu direito de defesa em face do Estado. ${ }^{37}$

35 TRF2, ACR no 200451020033610, rel. André Fontes, DJ 28/4/2008.

${ }^{36}$ Guedes, A presunção de veracidade..., op. cit., p. 262.

${ }^{37}$ Ibid., p. 259, grifamos. 
Na mesma linha de entendimento, os franceses Alain Pantley e FrançoisCharles Bernard citam inúmeros precedentes do Conselho de Estado Francês acerca do tema, entre os quais cumpre destacar aqueles que afirmam categoricamente que a condição de "alegação do Poder Público" não pode conduzir à imposição, contra o particular, do ônus da prova de fatos negativos ou da inexistência de certas circunstâncias alegadas pela administração. ${ }^{38}$

No Brasil, a jurisprudência, em importantíssima decisão do Superior Tribunal de Justiça, relatada pelo Exmo. ministro Luiz Fux, rejeitou a presunção de veracidade como forma de transferir ônus probatórios de fatos negativos:

PROCESSUAL CIVIL E ADMINISTRATIVO. MULTA POR INFRAÇÃO À LEGISLAÇÃO TRABALHISTA. EXEGESE DOS $§ \S 3^{\circ}$ E 4ํㅡㅁ DO ART. 630, DA CLT. COMPROVAÇÃO DE FATO NEGATIVO PELO DEMANDADO. IMPOSSIBILIDADE. NECESSÁRIO REEXAME DE PROVAS. SÚMULA № 07/STJ. VIOLAÇÃO AO ART. 535, DO CPC. INEXISTÊNCIA.

1. Inexiste ofensa ao art. 535 do CPC, quando o Tribunal de origem, embora sucintamente, pronuncia-se de forma clara e suficiente sobre a questão posta nos autos. Ademais o magistrado está obrigado a rebater, um a um, os argumentos trazidos pela parte, desde que os fundamentos utilizados tenham sido suficientes para embasar a decisão.

2. Afirmando o empregador a inexistência de horas extraordinárias de trabalho, não há como lhe exigir a comprovação dos documentos inerentes ao seu pagamento.

3. Discordando a Administração Pública da suposta jornada dita extraordinária, cumpre-lhe comprovar a infração à legislação trabalhista, constituindo o crédito inerente à sanção mediante a comprovação da ilegalidade, posto competir ao autor a prova do fato constitutivo do seu direito.

4. Assentando o empregador a inexistência de horas-extras, a fortiori, implica afirmar que não há nada a pagar e consequentemente documentos comprobatórios desse pagamento.

\footnotetext{
${ }^{38}$ PLANTEY, Alain; BERNARD, François-Charles. La preuve devant le juge administratif. Paris: Economica, 2003. p. 260.
} 
5. A autoridade somente poderia lavrar multa pela infração em si, quanto à ausência de pagamento pela jornada extraordinária, à luz da comprovação de sua existência pela entidade autuante e do correspectivo inadimplemento.

6. Deveras, a existência da efetiva ocorrência da jornada extraordinária é matéria aferível nas instâncias ordinárias em face da cognição restrita do E. STJ.

7. Recurso especial não conhecido. ${ }^{39}$

Cremos, por outro lado, ser compatível com a nossa Constituição um princípio de presunção apenas de legitimidade (compatibilidade com o direito) dos atos do Estado em geral, inclusive dos atos administrativos, sob pena de se comprometer sua autoexecutoriedade e a ordem social. É a mesma lógica pela qual as leis são dotadas de presunção de constitucionalidade.

Assim, com Gilmar Mendes (voto no MS 24268), é possível observar que o princípio da presunção de legitimidade dos atos administrativos se aplica tanto em favor do Estado, como dos particulares, de maneira que conjugado com os princípios da boa-fé e da segurança jurídica pode, por exemplo, impedir ou atenuar a geração de efeitos da declaração da nulidade de um ato administrativo que o tenha beneficiado.

O princípio da veracidade dos fatos invocados pela administração pública na edição dos seus atos deve, contudo, a nosso ver, apesar de tradicionalmente invocado entre nós - e hábitos muitas vezes levam tempo para serem revistos - , ser considerado como não recebido pela Constituição redemocratizadora de 1988, especialmente em face dos princípios da motivação e da presunção de inocência.

Nesse sentido, alvissareira no ambiente do direito administrativo latino-americano a Lei do Processo Administrativo Peruano, pois ao consagrar a presunção de veracidade dos fatos alegados pelo particular (art. 4o e 42) - o contrário do que a doutrina tradicional brasileira insiste em defender - e ao minudenciar os requisitos que os atos administrativos devem ter para atender ao dever de motivação (art. 6º ), responde amplamente às preocupações que na matéria devem imbuir um estado democrático de direito.

\footnotetext{
${ }^{39}$ AgRg no MS 11308/DF, rel. ministro Luiz Fux, j. em 28/6/2006, DJ 14/8/2006.
} 


\section{Referências}

BELTRÁN DE FELIPE, Miguel. Realidad y constitucionalidad en el derecho administrativo sancionador (segunda parte). Revista Jurídica de Castilla - La Mancha, 2006.

BULOS, Uadi Lammêgo. Constituição Federal anotada. São Paulo: Saraiva, 2007.

COSTA, Nelson Nery. Processo administrativo e suas espécies. Rio de Janeiro: Forense, 2003.

DALLARI, Adilson Abreu; FERRAZ, Sérgio. Processo administrativo. São Paulo: Malheiros, 2001.

FERRAZ, Sérgio; DALLARI, Adilson Abreu. Processo administrativo. São Paulo: Malheiros, 2001.

FIGUEIREDO, Lúcia Valle. Curso de direito administrativo. São Paulo: Malheiros, 2001.

GASKINS, Richard H. Burdens of proof in modern discourse. Yale University Press, 1975.

GOMES, Luiz Flávio. Sobre o conteúdo processual tridimensional do princípio da presunção de inocência. Revista dos Tribunais, São Paulo, v. 729, jul. 1996.

GUEDES, Demian. A presunção de veracidade e o estado democrático de direito: uma reavaliação que se impõe. In: Direito administrativo e seus novos paradigmas. Belo Horizonte: Fórum, 2008.

. A presunção de veracidade dos atos da administração pública e o processo administrativo: o dever de fiscalizar provando. Revista Interesse Público, v. 35, 2006.

IRELLI, Vicenzo Cerulli. Corso di diritto amministrativo. Torino: Giappichelli, 2001.

LOPES MEIRELLES, Hely. Direito administrativo brasileiro. São Paulo: Malheiros, 1993.

MOREIRA, Egon Bockmann. Processo administrativo: princípios constitucionais e a Lei no 9.748/99. São Paulo: Malheiros, 2000.

MOREIRA NETO, Diogo de Figueiredo. Curso de direito administrativo. Rio de Janeiro: Forense, 2009. 
. Curso de direito administrativo. 15. ed., 2. tir. Rio de Janeiro: Forense, 2010.

OSÓRIO, Fabio Medina. Direito administrativo sancionador. São Paulo: Revista dos Tribunais, 2005.

PLANTEY, Alain; BERNARD, François-Charles. La preuve devant le juge administratif. Paris: Economica, 2003.

SSTC 76/1990 e 138/1990 FJ 5, STC 212/1990, de 20 de dezembro. Ponente: D. Jesus Leguina Villa. Apud PONS CÀNOVAS, Ferran. Las medidas provisionales en el procedimiento administrativo sancionador. Madrid-Barcelona: Marcial Pons, 2001. 